\title{
Fulfilling the Promise of Sociology: Some Steps for Generating Reflexivity in Organizations
}

\author{
Marinus Ossewaarde \\ University of Twente, \\ Netherlands
}

\section{Introduction}

Sociology can be defined as the study of society, that is, as thinking, writing and talking about that elusive thing called 'society'. The latter concept is highly ambiguous and contested among different sociologists. The same goes for all the main aspects of social life, like the market, corporation, state, community, science, technology, law, and so forth, which are also sociologically approached in different ways. The ambiguous nature of society therefore means that sociology, just like economics or political science, is divided and pluriform. In this chapter, sociology is introduced as a social activity, not only because sociologists are very much embedded in social life in general and in organizations in particular, but also because their sociologies have the potential to change society, both constructively and destructively. The close relation between theory and practice, not always recognized by scientists, lays responsibilities upon sociologists, which the latter cannot discard without betraying their scientific vocation. The ambiguity of that which they try to know already manifests itself in the clashing sociological theories about society, and about what are perceived to be its distinctive elements.

Different sociological approaches to the study of society can be distinguished; their definitions of theory and science differ from each other. These various traditions can prove to be of great value to the reflexive sociologist who recognizes the ambivalence that is inherent to doing sociology. This awareness is the first prerequisite for a sociological dialogue and dialogical sociology, whereby clashing sociologies are allowed to interact, and eventually create new liberating perspectives and generate innovation. This dialogical approach does not only follow from the recognition of the ambiguous nature of society in general, and of organizations, be it a research lab, a business corporation, a public agency or an NGO, in particular, but also from the commitment to the European values of freedom and reason, as these have been understood by reflexive sociologists like C. Wright Mills, Alvin Gouldner or Irving Louis Horowitz. Dialogue is the playground par excellence for representing Socratic reason in all domains of social existence. Hence, it is only through dialogical activities and the institutionalization of dialogue, or what radical sociologists have called the 'publics', that sociology can develop as a science, and avoids the alliance with reifying forces.

\section{Four theories of society}

Sociology is defined as the study of society and hence delivers knowledge of all aspects of social existence, including laboratory, corporate, public, military, academic, legal, and so 
forth, types of existence. And hence it delivers knowledge for all agents, be it CEOs of companies, medical doctors in hospitals, legislators in states, consumers in markets, journalists in media landscapes, and so forth. What 'society' actually is, however, and, correspondingly, who or what sociology is to serve with its knowledge, is itself a sociological question to which there are diverse sociological answers. Society itself is a highly loaded sociological concept whose meanings have varied according to historical (typically national and religious) contexts, and have been subjected to debates and contestations. The definitions or understandings of sociology and of society are intimately related and interdependent. Hence, the specific perception of society has implications for the end, content and form of sociology. At the same time, the different types of sociology, as they have historically developed, determine the ways in which sociologists who adhere to them define and study society; in other words, the type of sociology determines the sociological vision of society. Furthermore, the definitions of sociology and the selfdefinitions of sociologists have implications for the ways in which they do their research, that is, for the development of concepts, for the methods used and the selection of data (Ossewaarde, 2012).

Four major and influential types of sociologists, and hence sociologies that define society in radically different ways can be distinguished. Positivist sociologists perceive society as mechanically governed, in line with Newtonian physics. Society is a complex of social relationships and historical developments that obey certain laws, just as physical things are ruled by the law of gravity. Along this line, there is no fundamental distinction between social mechanisms and natural mechanisms: both nature and society are causal complexes. Hence, in their view, the task of sociology defined as an objective, value-free and accurate instrument is to reconstruct these laws and explain social relationships as well as social conflicts in terms of causes. It confines itself to what is perceived as the material or empirical world, similarly to natural scientists; in this sense, positivist sociologists accept the approach or method of modern natural sciences as authoritative. They also tend to devote much time and energy to the refinement of scientific methods, particularly quantitative methods, which enable them to explain social mechanisms in more accurate ways (Levine, 1995: 96).

Functionalist sociologists see society as an organism, a metaphor borrowed from biology. Hence, society is not simply passive matter (like a stone) that undergoes certain laws of necessity, but is a living body consisting of organs that are all indispensable, and whose good functioning is essential to social existence in states, corporations, NGOs, hospitals, families, universities, and so forth. When functions are not fulfilled, for instance, when parents or families fail to bring up their children, scientists fail to grasp realities, police fails to create a safe and secure environment, or companies fail to generate jobs and profits, social order, and hence solidarity, tend to be undermined. Thus understood, sociology is itself an essential organ of society, having the function of discovering the functions of social organs, and hence, that which makes society be structured or ordered. The social function of sociology is therefore to acquire scientific knowledge about what makes social existence cohere, and hence, directly and indirectly, to prevent society from being destroyed by civil wars and revolutions, the prices of ill-functioning.

Marxist sociologists radically distinguish themselves from their positivist and functionalist counterparts in their perception of the inevitability of conflicts. They theorize society in the light of what they see as the history of class conflict; hence, living-together is a conflict 
situation that is defined by socio-economic inequalities, exploitation, alienation, and other forms of oppression that result from these inequalities. In the Marxist definition, a society at a given time is a reflection of a current state of affairs in an ongoing battle, peaceful or violent clashes, between those who have (or have more) and those who have not (or have less). According to this perspective, economic position determines the social positions of social actors; hence the distinction between the haves and the have-nots; between the powerful and the powerless. Sociology, like any science, is itself organized knowledge that is class-bound. It is a representation of a particular class; as most sociologists are typically lower middle class, sociology typically propagates the knowledge that is characteristic for this class. For Marxist sociologists, the dominant or established sociology is itself a manifestation of the current state of the class conflict; hence the task of the sociologist who has finally understood history, that is, that of class conflict, is to create intelligible reconstructions of class rivalries, and how society is destroyed and recreated through such conflicts.

Interpretive sociologists provide yet another portrait of society. For them, society is a cultural complex, a mosaic consisting of webs of meanings, symbols, values and beliefs. Religions, companies, universities, sciences, nations, markets, and so forth, are to be understood as dynamic cultural complexes, each having its distinctive set of values that inspire a distinctive type of social conduct. A particular cultural complex usually changes throughout history, and besides, it differs from other cultural complexes at a given moment. What makes a cultural complex be what it is and not that other one? This is what interpretive sociologists try to find out; they endeavour to understand the historically unique about a particular society, as compared with other epochs, but also with other cultural complexes in the same time period. Sociology, like science in general, is itself a cultural expression of a particular cultural complex, and its meaning changes with the mutations of the complex. Twentieth century sociology signified something different from what it can possibly signify in the twenty-first century. In other words, the cultural substance of sociologies, its ideas, language, ways of doing science, worldviews, and so forth, change as the society of which they are part also transforms. Interpretive sociologists try to make sense of such cultural transformations.

Those four different sociologies have introduced different theories of society, to describe, explain, uncover, reconstruct, criticize or interpret society. The very content and form of 'theory' differs per sociology. For positivist sociologists, given their definition of society as a causal mechanism, theory consists of the modelling of causal relationships, and is presented in the form of variables. The positivist theory of society assumes the form of a collection of variables - like nation, class, religion, age, sex, education, and so forth - that are deemed to be useful in presenting research findings. For functionalist sociologists, theory typically assumes the form of a realist typology or a scheme that provides an abstraction of the organism under investigation. Emile Durkheim's solidarity types (mechanic and organic solidarities), for instance, or Robert Merton's 'local' and 'cosmopolitan' real types, enable functionalist sociologists to grasp distinctions between structures, and transitions from one social structure to another. Functionalist schemes provide a systemic modelling of certain organic functions that a particular society (say, a global capitalist society) must meet to be able to flourish. Marxist sociological theory assumes the form of a critique; it unmasks and criticizes capitalist forces that maintain a capitalist status quo, and hinder the development 
of a working class consciousness. Hence, bourgeois ideologies like (neo-) liberalism, nationalism and cosmopolitanism are denounced. For interpretive sociologists, theory consists of ideal types that enable sociologists to empathically interpret the cultural meanings of social experiences, and to make sense of phenomena via the application of ideal types. Interpretive sociology has emerged from Kantian idealist thought and, correspondingly, rejects the materialist and realist ways of theorizing.

In their approaches to societies, these sociologies tend to discern and stress diverse dimensions of social life, and evaluate them differently. Positivist sociologists focus, in their own materialist theory of contemporary society, primarily on the economic and technological aspects, which it perceives as determinants of (material) progress. Hence society is modelled as an industrial (either capitalist or socialist) nation, one in which positivist scientists, engineers, bureaucrats are powerful actors of social control, and machinery and policy are key institutions. For functionalist sociologists, it is especially the increasingly complex solidarity structure that is relevant. In the functionalist theory of contemporary society, society is perceived as an individualized (typically capitalist) nation, in which rights, contracts, commerce, interdependencies, trust, and reciprocities are key elements that make modern social bodies flourish. In Marxist sociology, the economic and technological dimensions of society are strong determinants, just as in the case of positivist sociology, but unlike the latter, it appraises them differently. Capitalism is the breeding ground for revolutions, which will only cease when a historical condition of absolute social equality has been reached, and the distinction between rich and poor has been abolished. As far as interpretive sociologists are concerned, it is culture that is of primordial importance for social existence in organizations. Hence, the cultural complex that is called society typically a nation - is actually threatened by anti-cultural or nihilistic forces like technology, industry and bureaucracy. Contemporary society shows tendencies towards cultural regress, a condition that Max Weber grasps in the metaphor of the 'iron cage', which refers to the imprisonment of dwarfed individuals by systems of technical control.

\begin{tabular}{|l|l|l|l|l|}
\hline & Positivism & Functionalism & Marxism & $\begin{array}{l}\text { Interpretive } \\
\text { sociology }\end{array}$ \\
\hline $\begin{array}{l}\text { Theory of } \\
\text { society } \\
\begin{array}{l}\text { Scientific goal } \\
\text { Theory } \\
\text { Society today }\end{array}\end{array}$ & $\begin{array}{l}\text { Mechanism } \\
\text { Explanation } \\
\text { Causal model } \\
\text { Technological }\end{array}$ & $\begin{array}{l}\text { Organism } \\
\text { Uncovering } \\
\text { Real types } \\
\text { Individualized }\end{array}$ & $\begin{array}{l}\text { Class conflict } \\
\text { Criticism } \\
\text { Social critique } \\
\text { Global } \\
\text { capitalist }\end{array}$ & $\begin{array}{l}\text { Cultural complex } \\
\text { Interpretation } \\
\text { Ideal type } \\
\text { Global culture }\end{array}$ \\
\hline
\end{tabular}

Fig. 1. The four sociologies

\section{The reflexive turn in sociology: Eembracing ambivalence and ambiguity}

Sociologies, like the other social sciences, are organized within a given society, that is, within a given technological order, solidarity structure, class or culture, in a certain historical epoch. Sociologists are part of the society that they theorize themselves, and not somehow 'outside'. This awareness of the social, cultural or public imbedding of sociologies and sociologists has been pointed out by reflexive sociologists. Sociologists like C. Wright Mills and Alvin Gouldner have shown how theories of society rest on ideological biases, 
prejudices, and taken-for-granted truisms, which are often inherent to the social condition in which sociologists find themselves. The technological orders, solidarity structures, class conflicts and cultural complexes of the positivists, functionalists, Marxist and interpretive sociologists respectively typically rest on the nation or class conflict as immediate context. As long as sociologists are glued to their own research traditions, they will be incapable of transcending their prejudices. Ulrich Beck and Edgar Grande (2010) note that as most sociologists, through their prejudices and old routines, theorize society as a nation, which implies that they non-reflexively collect data at the national level, typically to be able to continue with their cross-national comparisons (Chernilo, 2011). Such un-scientific malpractices in scientific research enforce the national prejudice, and maintain established categories as well as dominant theories of society, as if they were the only possible ones.

Reflexive sociologists perceive the ideological bias in so many theories of society as fundamentally anti-sociological. There is no room for ideology in sociology; or, as Alvin Gouldner (1976: 19) puts it: 'sociology and ideology are competitors'. Beck and Grande (2010) seek to transcend the ideological bias of nationhood in sociological research 'methodological nationalism; as they call it - in sociological conceptualization. Instead, they propose a 'methodological cosmopolitanism' that takes into account globalization processes at work to cosmopolitanize national existence in worldwide organizations, particularly transnational corporations, global media, NGOs and virtual networks like Facebook and Youtube. Methodological cosmopolitanism, they hope, should enable sociologists to reflect upon social processes - particularly globalization processes - that, precisely because of the dominion of the national categories, have been neglected in established theories of society. This cosmopolitan turn in sociology does not mean that the nation-state, or class for that matter, is no longer relevant in conceptualizations; but it does imply that the established sociological categories of social existence are insufficient to take into account globalizing processes that cut through, and undermine, all previously (historically) established collectivities. Society is re-theorized as a world society, which involves clashing cultures and rationalities and multiple modernities.

Methodological cosmopolitanism does try to transcend, to some extent, existing scientific demarcations, and in this sense, questions some existing ideological biases and (typically class-based) prejudices. However, even cosmopolitan theories of world society are not exempt from ideological commitment. Very much like their nationalist predecessors, they also have too little room for the ambivalence inherent to the theorizing about society. Reflexive sociologists emphasize that in theorizing society, ambivalence is to be embraced, as something inevitable because of the intricacies of social life. The uncomfortable possibility of having to assign a social experience to more than one category, be it nation, class or world, is thereby denied (Bauman, 1991: 1). On a more fundamental level, then, the task of sociology, as Robert Merton (1976: 54) puts it, is 'to lay siege to the problem of ambivalence', which is not the same as trying to conquer it. Rather, Merton sees it as an urgent matter to make the very problem of ambivalence a sociological issue. A class consciousness, for instance, insufficiently understands the wide variety of social experiences, and fails to see the paradoxical tendencies of various, clashing social processes at work in the becoming of societies. Prevailing theories of societies tend to reify, that is, objectify abstract concepts such as nationalism, socialism or cosmopolitanism; or else, they take these for granted. In sum, reflexive sociology rejects all ideologies as scientific obstructions or diseases of the mind. 
Ideologies simplify reality and illegitimately fail to embrace ambivalence as a side-product of theorizing society (Bauman, 1991).

Reflexive sociologists not only embrace ambivalence in the theorization of society, but, correspondingly, they also emphasize that social existence is fundamentally ambiguous. Donald Levine $(1985: 8$; 17) stresses that, for sociologists to become reflexive, they are called to grasp the imprecision and multiplicity of meanings of social experiences. Embracing ambiguity implies recognition that sociological concepts, such as nation, anomie, alienation, bureaucracy, freedom, and so forth, that are designed to represent specific social experiences, are essentially contested. And their contestation must be embraced because social existence is ambiguous, that is, social life is filled with opposing tendencies in everything that ties and divides people (power, ideologies, beliefs, religions, classes, ethnicities, education levels, salary scales, and so forth), makes that society is perpetually moving, with arbitrarily fixated categories, false certainties and bygone hierarchies dissolving in random contingencies (Bloch, 1983; Bachika and Schulz, 2011). According to Levine, embracing ambiguity, and thereby be reflexive, is to disentangle the multiple meanings of concepts and to represent experiences through plurivocal modes of representation, using parables, allegories, metaphors, and so forth.

Reflexive sociologists have made use of, and radically criticized, the four sociologies. They point out the danger of reification, of imprinting a particular theory of society on social reality. They criticize the objectification of social existence, whereby so many dimensions and so many movements are left out. They demolish theories that ignore the very ambiguity of social existence, as, for them, social existence cannot be defined by a few, arbitrarily selected, social processes or phenomena. They reject one-dimensional thinking in sociology. They reject the idea of society as a coherent entity, be it a nation, class or world society, in which a presumed whole society comes to determine which processes, phenomena or experiences are to be perceived as relevant. The message of reflexive sociological voices, which are not necessarily fully developed sociologies, is critical: they stress the need to unmask the distortions of existing theories and judgments of sociologists. Hence, reflexive sociologists often restrict themselves to formulating the fragmentation of social experiences, and unceasing disruptions that undermine any social stability, in the scientific form of sociological fragments. Through speaking and writing about society in fragments, and hence treating data as interesting splinters of social existence, reflexive sociologists attempt to deal responsibly with issues of ambivalence and ambiguity, against all attempts of simplification that they consider to be fundamentally biased (c.f., Levine, 1995: 7; Agger, 2008).

\section{The scientific form of reflexive sociology: Dialogue}

The domination of one type of sociology, as well as its professionalizing within the boundaries of its own particular world of science, freezes sociological development; and, would nearly make one believe that sociology has reached its goal, so that it only needs to refine its tools of enquiry. Against this one-sidedness, reflexive sociologists have stressed that it is instead through contradictions, scientific diversity, rivalry, clash of doctrines, and Methodenstreit, that sociology develops (Merton, 1976: 116). Sociology develops through the generation of reflexivity. The fragmentation and provisional nature of all sociological knowledge, which follow from the ambiguity of social existence, make a dialogue that relates different sociologies from the present as well as from the past highly appropriate. 
Such dialogue is an open form of communication in which sociologists refuse to impose their sociological cultures and ways of doing sociology on each other. According to such a dialogical perspective, sociology, as contrasted with ideology or sophistry, moves and evolves through a clash of minds, ideas, scientific languages and methods, in and through dialogues (Levine, 1995: 327-328; Ossewaarde, 2010a; Ossewaarde, 2010b).

In this way, sociologists from clashing, rivalling sociological positions are enabled to make contributions to the conversations of each other, and contribute towards moving beyond contradictions and fragmentations in the creation of newly envisioned social alternatives (Gouldner, 1976: 21). Sociological theorizing that has been informed in and through dialogical relationships of sharing and reconciling can better fulfil its social responsibility or its scientific vocation. Such theorizing through dialoguing assumes the scientific form of playful intellectuality (c.f. Agger, 2008: 429), a childlike, Socratic, playfulness that most great sociological theorizers and innovators manifest. The dialogue between sociologies is a kind of compensation or antidote to the fragmentation of sociological knowledge, by bridging sociologists and sociologies, without enforcing a dominant sociology, theory of society, method, or definition of science. Instead, dialogue has the potential of revealing the ambivalence of existent sociological knowledge, but also of overcoming deadlocks through patient questioning, exploration, and self-questioning, with the knowledge that absolute certainty of sociological knowledge is not possible and even not desirable. The dialogical sociologist is highly vigilant of abuse of power, which often rests on the claim to absolute knowledge.

A flourishing sociology, then, depends on the availability of the appropriate social form the dialogue - that enables sociologists to sustain reflexive scientific discourses about social worlds (Gouldner, 1973: 96). The establishment of dialogue is therefore a precondition for genuine (that is, reflexive) sociological existence, one that is devoid of ideological bias, as far as this is possible. Originally, in ancient Athens, (Socratic) dialogue was conceived as the social form most appropriate for developing scientific insights. It was through dialoguing that science could come to flourish. For Plato, the Socratic dialogue is the opposite of the oration, which he identified as a social form in which ignorance and bias comes to be publicly represented (Voegelin, 2000: 66). In other words, science, and hence sociology, is best organized in dialogues. Science comes to flourish through dialoguing, and it is destroyed through the destruction of dialogue, either from within (via scientific tribalism) or from without (via the invasion of non-scientific forces). Through the establishment of dialogue, sociology can develop as a genuine conversation, sociological otherness can be accepted, and sociologies can provide a liberating perspective on each other. Sociological freedom is optimal when neither of the sociologies is insulated from others, when no sociology is repressed or marginalized, when all are allowed to provide critical perspectives on each other, and when all are brought into a dynamic, vitalizing tension with each other (Gouldner, 1973: 361).

Such dynamism, Alvin Gouldner (1973: 96) emphasizes, is socially created through the dialogizing activity of sociologists; the latter are called 'to create tension, conflict, criticism and struggle against conventional definitions of social reality, to extricate oneself from them, and to undermine their existential foundations by struggling against the social conditions and institutions that sustain them.' Through dialoguing, Gouldner asserts, sociologists not only reveal the ambivalence in dominating theories of society, but they also contest the 
practices and social contexts that sustain the theories or obstruct the dialogue. Conversing sociologists cannot tolerate any preconceived view or conceptual foundation on which society, and hence sociology, rest. The practice of dialogue can therefore recall and confirm the inseparability of theory (modelling of society) and practice (shaping society in accordance with such models); in other words, sociologists are made aware of the social consequences of their practices, which is to say that they develop reflexivity in their mindsets. Indeed, sociology not only entails theorizing society, but also shaping it; and, since all theories of society have a practical implication for governing societies, sociologists must, according to reflexive sociologists, assume responsibility for the practical ends to which their theories and research findings are used (Gouldner, 1976: 182). In other words, reflexivity entails that sociologists are obliged to make sense of their own work. They cannot legitimately do their scientific work and then leave it to the public to deal with their scientific results (c.f., Sennett, 2008: 5).

Doing reflexive sociology, accordingly, requires an awareness of the possible practical implications of theories and methods, of the possible ways in which sociology or research can be used or misused by others, in particular by elites who are most powerful in shaping society. Reflexive sociological research, in order to be as free as possible from blind spots, moves in a sort of spiral or pendulum between the study of society and its elements (empirical objects), and sociological dialogue, and back to the same study with renewed minds. Such is the core of reflexive sociology. Reflexivity means that sociologists are aware of their own subjectivities and social backgrounds, represented in their own research, and are conscious of how they participate in constructing their own research objects (Gouldner, 1973: 105). Such reflexive self-examination is one of the virtues that are the prerequisites for a fruitful dialogue. Reflexivity demands from sociologists that they be willing to live in intimate tension with the social things they speak and write about, therefore excluding all forms of complacency and desire for absolute certainty. Clearly, such a sociological virtue, just as sociological knowledge, can only be striven after without the illusion of ever possessing it completely.

\section{Sociological dialoguing: The scientific activities of contradiction, negation and critique}

Sociology, like all social activity, can best be compared with movement; it moves in and through dialogues, through the contests of clashing theories of society. The recognition of the contradiction between theories is a starting point of sociological development, at least as far as the more reflexive forms of sociology are concerned. It is the first dialogical activity, a scientific activity that pushes sociologists to move, intellectually speaking, beyond their own theories and methods, towards a more truthful understanding of society and its features. The contradictions between the theories of society are, accordingly, not something that sociologists must get rid of to arrive at a better comprehension of society. Instead, to hold incompatible sociological theories in tension is to appreciate sociological otherness, which is a prerequisite for organizing a dialogue in the first place. As Richard Sennett (2008:6) puts it, good science does not settle a question or solve a problem: instead, it unsettles, bequeaths disquiet, invites argument. Sociological dialoguing is a deliberate attempt to unsettle research conclusions. This scientific activity is a fight against all simplifications and 
reductions of paradoxical, moving, and ambiguous reality in scientific modelling and analysis (Ossewaarde, 2010a).

The reflexive sociologist who recognizes the irreconcilable contradictions between the various sociologies, between their peculiar concepts, jargons, methods, mind-sets, worldviews, and so forth, can choose to draw on all these traditions to form an own scientific approach to social life. This is not exactly the same thing as eclecticism since the European values freedom and reason, and more specifically, the sociological traditions that represent them, remain the most authoritative in such acrobatic exercises. In any case, the reflexive sociologist knows why the functionalist sees society as an organism, and on which assumptions this rests; the same reasoning holds for the other sociologies. Though it is incoherent to say that all these perspectives are equally 'true', the sociologist can use certain insights and languages in particular cases. Hence, the positivist concept of causal mechanism can be useful to explain how the level of education is linked to social positions. Such sociologists, to repeat once again, are not impartial observers; there is an ongoing dialogue between their own visions or values, and rivalling others. In this way, they are obliged to question and re-question their commitments, hence avoiding the pitfall of reification. Hence, the attempt is not made to (literally) grasp society as a whole - in some complete, all-embracing, harmonious and systemic model of social order - but the somehow humbler endeavour is made to try to understand social aspects, dimensions, phenomena, or processes. This is how the different sociologies can be sources of knowledge.

Once the contradictions are recognized, certain theoretical claims - that, of course, always have practical implications - can be, ought to be, negated, so that theories can be 'purified' of well-established falsehoods and bias (Gouldner, 1976: 21). Negation is therefore a second dialogical activity. Through negation, the obstacles to theoretical development, such as arbitrary fixations, dogma, prejudice, cliché, arbitrary predispositions, and so forth, are removed and reflexivity is developed. Negation is the creative destruction of a (typically predominant) theory of society, with the view of creating a new theory. It is a demolishing scientific activity, needed to make a new scientific creation possible, in the form of a new theory of society that matches more with a current or new state of social existence. Hence, negation is inspired by social transformations, in the sense that the necessity of negation becomes obvious when some theorization turns outdated in the sense that such a particular theory of society no longer matches with changed social realities.

The negation of theories of society, however, does not imply a total demolishing. The creation of new theories may well contain elements of the old theory of society. On the contrary, negation does not imply that all known categories - such as the nation-state, class, capitalism, democracy, university, science, media, technology, European identity, and so forth - can be discarded. Instead, elements of the outdated theory are subsumed in the new theorization and are invested with a new significance, in a new movement, towards a new becoming of a new society (c.f., Couldry, 2009; Urry, 2010). In other words, negation implies both destruction and continuation. The four sociologies cannot be discarded as superfluous surpluses without damaging the sociological enterprise. Also in the act of negation, reflexive sociologists still stand on the shoulder of the great founders of sociology and work to constantly revitalize the sociological tradition as a representation of the European value of reason (Ossewaarde, 2007b). 
A third dialogical activity, closely connected with negation, is the critique of the social conditions of sociological theorizing. Several sociologists, such as Anthony Giddens, Ulrich Beck and Zygmunt Bauman, have put forward 'critiques of modernity', and have developed new concepts like 'postmodernity' and 'late modernity', to point out that (early) modern theories of society, or particular concepts, that used to authoritative have lost their validity. Robert Nisbet (1966: 318), for instance, concludes that Ferdinand Tönnies' well-established Gemeinschaft-Gesellschaft distinction has lost much of its theoretical vitality for studying social experiences in the 1960s. Tönnies' ideal types were once useful to grasp the movements of society, but, the further individualization of the individualized society, has implied that the collectivities of the Gesellschaft, including the nuclear family, gender, nation, citizenship and class, have turned liquid (Beck and Beck-Gernsheim, 2002: 18-19; Bauman, 2003). The ideal types that used to make it possible for sociologists to interpret the meaning of individualization have become 'zombie categories'. As social existence increasingly takes place outside the realm of classes, gender, nuclear family, or nation, these collectivities of the individualized society are accordingly increasingly insufficient to understand social experiences and identities. Instead, sociological concepts such as selfmanagement and lifestyle have been coined or re-introduced as more appropriate for enquiry into current social affairs.

According to reflexive sociologists, sociology therefore moves, or develops, as a science through three dialogical activities: recognition of contradictions, negation and critique. Through these activities, sociologists are able to move from practice to theories, and back to practice, back and forth; in this way, they try to do justice to rapidly changing social worlds. The problem of outdated concepts or theories lies not in their being outdated or old, but in the fact that sociological theories also constitute changing forces. By clinging on to old concepts, theories might simply become redundant, irrelevant to social practices, but they can also be harmful if they are used by policy makers for instance. They can serve to freeze social existence, or ignore important social dimensions. The identification of the vigour and weakness of current social structures, the denunciation of structures that are closed to reason and freedom, and the conceptualization of social alternatives constitute a dialogical sociological ethos. Several sociologists, however, have noted that in the current era of global capitalism, this particular sociological ethos is not at all appreciated by those in power, who hold power in the current acme of stability and would lose it if familiar certainties were undermined (c.f., Burawoy, 2005a: 263). Given the concentrations of power in the current era, there is a rather strong pressure from the power centres, ideologically supported by the ideology of neoliberalism, to destroy all imaginable social alternatives to the current state of (globalizing) social existence (Bauman, 1991: 269).

\section{The alertness of reflexive sociology: Fulfilling the promise of sociology}

Reflexivity implies the awareness of the practical implications of sociological research and knowledge, which further necessitates posing the questions regarding the ends, the beneficiaries and victims of knowledge. In other words, as Robert Lynd ([1939], 1970), simply put it, for what and for whom do sociologists produce scientific knowledge at a given time and in a given historical era. Precisely because sociology entails both theory and practice - and, accordingly, has, like all science, a social dimension - doing reflexive sociology involves intellectual and emotional adherence to certain values (rather than to 
certain powers) that sustain or promote sociological dialogue. In other words, a value-empty sociology is not only a hollow concept, but is also undesirable and dangerous, since such sociology is typically allied to ideologies. C. Wright Mills ([1959], 2000) argues that the European values, reason and freedom, are important criteria to distinguish between true, liberating knowledge that is connected with the social form of the dialogue, and false, ideologically motivated knowledge that is connected with the social form of the orator. According to Mills, sociologists are, in their scientific activities, bound to the Delphic oracle, to a 'promise' as he calls it. This is the promise to expand the role of Socratic reasoning and genuine freedom in social affairs, to be achieved through developing a reflexive 'quality of mind' that will help people, including managers, professionals, citizens and consumers, 'to use information and to develop reason in order to achieve lucid summations of what is going on in the world and of what may be happening within themselves' (Mills, 2000: 5). This quality of mind is not the exclusive property of reflexive sociologists. Instead, the promise of sociology is to 'sociologize' the minds of a variety of people or 'publics' as Mills calls them (Ossewaarde, 2007a) - encounters where sociology and appliers of sociological insights come together.

Sciences, in general, and sociology in particular, are in the first place a representation or embodiment of the European value of reason. Reason is the Socratic, dialogical capacity to search for truth, involving the intellect, imagination, consciousness, and empathy; it ultimately finds its expression in self-knowledge, and knowledge of the other, these two forms of knowledge being inseparable and intimately related. For reflexive sociologists, reason is not a one-off instantaneous faculty, but is developed through dialoguing; dialogue is the playground of reason par excellence. Irving Louis Horowitz (1993: 144) notes that the belief in the goodness of representing the value of reason in society, through dialoguing, and the corresponding Delphic quest for self-understanding as a European cultural force, ought to inspire scientific conduct: 'if one cannot believe in social science as a higher rationality, then all is lost'. Without Socratic reason as a supreme value, science is indeed devoid of intellectual and moral substance; and hence degenerates from being a cultural force into being a mere instrument that can serve all purposes, including destructive and oppressive causes. A 'higher rationality', however, constantly exposes people, including power holders, to scrutiny, and to the uncomfortable realization that, given the fundamental scientific obligation to embrace ambivalence and ambiguity, there is no simple solution to certain situations, no foolproof choice, and no social order that is exempt from reification (Bauman, 1991: 44-5).

As a manifestation and servant of reason, sociology is a continuation and elaboration of the permanent Delphic quest for self-understanding; there can be no science (knowledge) without self-knowledge. Sociology, Alvin Gouldner (1973: 126) says, is a social activity in pursuit of 'the ancient human aspiration for self-knowledge. If that is not a high calling, then none is.' Sociology can be both the study of society and the aspiration for self-knowledge, also within organizations and through work, because the self and social life, that is, social processes and activities, are related. To fulfil the promise of sociology in organizations is to develop a quality of mind that would enable people, say, managers and professionals to locate their organization within a historical period. It is to link the most remote structural transformations (such as globalization or technological revolutions) to the most intimate features of their own existence in their organization. And it is to identify the major crisis of 
institutional arrangements (like the crisis of corporate governance systems) and to discover the issues of stakeholders and organizations in our time (issues like bonuses, alienating methods of production, enveloping monitoring techniques, international anarchy, and so forth). Fulfilling the promise of sociology implies having the key values of reason and freedom at the centre of organizational concern. Understanding society, including understanding organizations, also means understanding the values - typically transmitted through social channels - that constitute, inspire and move selves in organizations. A reflexive sociology that takes the Delphic quest as the cornerstone for its own intellectual and moral enterprise, inside and outside sociology (in banking, journalism, management consultancy, marketing, public agencies, buying and selling, and so forth), integrates questions of values in all activities (c.f., Goldfarb, 2005: 290-291).

The founders of sociology, including Tocqueville, Durkheim, Veblen, Mosca, Simmel and Weber, have noted how the flourishing of reason in social affairs is undermined by the rationalization of social existence. Rationalization refers to the modernization process of eliminating all social ambiguities through various forms of technical control mechanisms; in this way, one particular definition of society, which facilitates and sustains a particular ideology or cause (peace for instance), dominates at the expense of all others. This bureaucratic mode of expression, which includes codification, protocolling, hand-booking, categorization, schematization, registration and quantification, has little capacity for tolerating ambiguity, owing to its incapacity and unwillingness to generate dialogical reasoning and reflexivity (c.f., Levine, 1985: 53). In bureaucratic structures, of states, corporations, hospitals, universities, NGOs, armies, churches, and so forth, preoccupation with control, certainty and methodological and legal rigour takes precedence over intellectual substance and public significance of European values. Bureaucracies function to create a world free of ambiguity, a transparent society of rational (or rather, technical) choices in which means are adjusted (efficiently, effectively and legally) to objectified political or ideological ends (c.f., Bauman, 1991: 230). Such a rationalized and ideologized society, however, is stuck in the ice of the cold and lifeless world of reifying and hopelessly simplifying and reductionist theories.

Bureaucracies prefer fixed categories and well-known variables to ambivalence and dialogues. They propagate compulsive identifications with a certain theory of a rationalized society, with the help of positivist sociology in which the ambivalence of social categories is conveniently denied. The used conceptual schemes and methodologies, characterized by their strictly univocal modes of representation in one-dimensional terms, are oriented to constructing precise information regarding social processes and their breakdowns (Levine, 1985: 8). In other words, bureaucracies represent a mind-set that can only deal with the superficial appearances of society, and not with the deeper structures that are constituted by contradictions, cultural factors or solidarity bonds. Therefore, sociologists like Horkheimer and Adorno, Lukacs, Mills and Gouldner have denoted bureaucracies, similarly to ideologies, as forces of unreason, as eclipses and destructions of reason and science. That is to say, the rationalization (that is, bureaucratization) of social arrangements expropriates the very intellectual, moral and political capacity to act as a free person - including free politicians, free managers, free entrepreneurs, free professionals, free media, free citizens, free consumers and free scientists - in society and its organizations (Mills, ([1959], 2000: 169; 173).

When scientific research is dictated by bureaucracies, positivism is destined to become predominant; the latter is namely the most applicable as bureaucratic tool. Hence, it is also 
no surprise that bureaucracies typically sponsor positivist research; and as long as social arrangements are being rationalized, the tendency to fund and favour positivism - hence undermining the dialogue between the sociologies, and enabling one kind of sociology to be dominant - is hard to stop (Horowitz, 1993: 141). The positivist theory of society is one of a rationalized society, a bureaucratically controllable mechanism devoid of ambiguities. Positivist sociology is useful for further rationalization efforts, for improving bureaucracies, enhancing their effectiveness in further annihilating ambiguity. Reflexive sociology is organized to resist rationalization pressures, which includes resisting the pressure of being included in bureaucratic structures. The promise of sociology can only be fulfilled if sociologists are willing to adhere to European values rather than abiding by bureaucratic demands or value systems of dominant powers that control the bureaucracies; and when science funding administrators, businessmen and foundation officials do not decide what is worthy to be studied. This scientific commitment to the European values does have its prices, such a permanent, tiresome struggle, and exclusion from academic settings that are also dependent on these powers for their survival (c.f., Shils, 1980).

Once it is recognized that all social activities, including scientific activities, are many-sided, it becomes illegitimate for sociologists, given the promise and call of sociology, to work with wooden, fixed, cut and dried, concepts, simple uniform variables that are seen to be immutable (Bloch, 1983: 284). In sociological activity, particularly in dialoguing, the reflexive awareness of the ambivalence of existing theories, blind spots or personal prejudices, and of the (latent) desire for certainty is a prerequisite. In and through dialogue, sociology moves through contradictions. It does not move linearly to some apex, but it moves dynamically, as a process of perpetually becoming something new. Sociologists are called to do justice to the ruptures, catastrophes and troubles of social worlds, those non-linear transformations that bureaucracies fail to see, seek to halt or simply tend to trivialize. Political or ideological ends are perceived to be better served when social words are made graspable and manageable. Reflexive sociology has the potential to contest such closing of the mind, out of commitment to the Delphic oracle, in the fundamental belief that without this commitment despotism and barbarism are destined to follow through the employment of value-empty and nonreflexive science. Reflexive sociology holds the key in expanding the role of freedom in social affairs because it alone enables its holders to become aware of their own unreason, prejudices and bias in their claims, teachings, writings, strategies, policies, evaluations and consults; and it makes holders sensitive to how sociology is used or misused in the destruction and creation of realities, thereby achieving summations of what is going on in the world and of what may be happening within themselves.

\section{Locating reflexive sociology in society: The alliance with publics}

Sociologists can contribute to the construction and destruction of social worlds; they are involved in transforming daily life and in creating a new society, new ways of making the European values flourish (Gouldner, 1973: 105). If sociology is to have value as a representation of the European values in society, that is, is to be constitutive for people's self-understanding, self-organization and self-government, then it must enter public debates and inform public opinion in all realms of social existence. In this way, the dialogue between sociologies is extended to a public dialogue, in which sociology is a partner; such a public 
sociology is no longer simply the affair or possession of some intellectual elite, but becomes the potential source of civic education for both rulers - politicians, governors, legislators, judges, administrators, managers - and ruled - citizens and employees. Reflexive or dialogical sociology can contribute towards a reasonable social cohesion, for instance, by revealing the solidarity structure. If this is a task for sociology, its call or promise, then sociological and social lives cannot be lived separately; hence, sociologists cannot live in their academic ivory towers. But at the same time, they cannot become civil or corporate servants, at the service of the ruling powers. In this sense, their roles are not given, fixed or certain; they, or more precisely, their ideas - for which they assume responsibility - have to permeate social structures, including political ones, without giving the reason and freedom.

Sociologists, therefore, not only endeavour to understand the world, but also to make it liveable, while being extremely vigilant of the ideological snare that can underlie ambitions to change the world or to solve problems. A dialogical sociology presumes democracy or publics (Ossewaarde, 2007a; Ossewaarde, 2010b). The latter concept, coined by C. Wright Mills, can be defined as dialogues organized in society, institutions or situations in and through which people can publicly express and receive opinions, and respond. Through such interaction, it is expected that they are able to form informed, reasonable opinions, independently of prevailing systems of authority, so that the force of the better argument comes to reign (Mills, 1956: 303-4). Publics are not so much concrete places or organizations as opportunities for coming together, for conversing and disputing, for realizing the promise of sociology in concrete situations of work, citizenship, consumption, and so forth, and thereby make their qualities of mind, their reasoning, publically relevant (Habermas, 2001: 27). Publics are based on the assumption that knowledge can be acquired through dialogical interactions in organizations, through friendly disputes in which people are actively involved, learns to listen and speak, critically and reflectively. It is, of course, also assumed that people have an active commitment to European values; the contrary namely guarantees mass events in which all sorts of unreason, such as populism and demagogies, can triumph in organization and management. Publics open dialogical opportunities for informed discussion about pressing problems, provoking conversation and deliberation, triggering real innovation and renewal. They enable people, say employees, with opposing values and different points of view to converse with each other, facilitating mutual understanding and compromise, and respect, tolerance, fair-mindedness and the willingness to be persuaded and change one's mind (Goldfarb, 2005: 282; Smith, 2009: 94).

Mustafa Emirbayer and Mimi Sheller (1999: 155) note that 'publics signify rational-critical argumentation and collective will formation regarding the paths along which the state, economy, and civil society itself are to develop.' Publics, thus understood, somewhat resemble ancient Greek city-states (re-publics); they constitute the substance of any democratic society. Examples of publics include open assemblies, town meetings, conferences, citizen juries, random samplings that bring a diversified body of citizens (typically between 12 and 160 citizen) to discuss public (especially controversial) issues (Smith, 2009: 28; 79). Such publics constitute countervailing forces against bureaucratic machineries. The absence of publics in society is a sign of a lack of democratic substance, of the underrepresentation of the value of reason, the representation of unreason (in the form of ideologies, reifications, phobias and hysterias), and the presence of power concentrations. In other words, the absence of publics signifies the absence of European values in social conduct and in organizations. 
C. Wright Mills (1956: 274) notes that 'the decline of politics as genuine and public debate of alternative decisions' that Michael Burawoy (2005b) also witnesses, is the result of the bureaucratization of social existence, in which the European values increasingly lose their authority, and reflexive science is no longer supported by social (dialogical) conditions. With the decline of publics, that is, the decline of (the intellectual and moral substance of) democracy, Socratic reason tends to be eluded, and hence sociology tends to lose its capacity or possibility to influence public issues of structural relevance. The decline of democratic politics, that is, the decline of genuine and public debate, and consequently the decline of reason and the rise of mindlessness, ideology and phobia, leads Alvin Gouldner (1973: 1678) to conclude 'it is the quality of mind, not politics, that confronts us with the deepest abyss'. As publics (and hence democracy) decline and bureaucracies rise, bureaucratic concerns, in particular, corporate and military interests, come to dominate social existence. Mills (1956: 304) notes how corporate strategies, marketing, publicity, entertainment, bribery, intimidation, secret surveillance and so forth, often based on misuses or abuses of sociology, all reinforce the destruction of democratic publics and the enforcement of bureaucracies - organizations in which the governed are perceived as passive workers, consumers, spectators, clients or property owners, instead of as political actors.

Since a dialogical sociology is dependent on the publics in order to safeguard the European values, it first has to revive the very conditions that make the development of publics possible. Hence, bringing sociology to the publics, to extent the promise of sociology to non-sociologists (not to live of sociology, but to live up to the promise of sociology in publics), goes hand in hand with the revival of the publics, that is, of the revaluation of the European values of reason and freedom. This revival becomes all the more urgent as trust in bureaucratic elites is lost, (early) modern bureaucratic structures in states and corporate sectors (particularly in the capital sectors) tend to dysfunction, and public anxieties and moral panics tend to spread with increased mindlessness of managers, professionals, citizens, and so forth. Reflexive sociology is significant in organizations in the sense that it organizes mindfulness, enabling its holders to become aware of the bias in planning, strategies and designs, in close tension with the objects they are dealing with; and to identify the values at stake when using their models, formats, methods, jargons, approaches. Dialoguing in publics fulfils the promise of sociology within the confines of organizations in the sense that dialoguers, in practicing the dialectic or friendly art of dispute, are, in the construction of their planning, strategies and designs, able to perceive and think beyond the actual, conventional and established understanding and expected, forecasted or hoped future. Also, dialogues propel stakeholders towards changing, creating new realities - realities in which reason and freedom may come to play a greater role in management and organization, so that organizations may be experienced as less stupefying and less oppressive.

Richard Sennett (2008: 33) observes that, ultimately, publics also support better corporate performances, turning organizational existence into a more mindful and liberating experience for stakeholders. Sennett gives the example of Nokia, which, in order to generate technological innovation, instituted the dialogue as organizational form. Its management created a dialogical community, a public, including its engineers, salespeople and designers, who were invited, as individual employees, to formulate their issues in their own terms, to consider extremes, and to challenge and dispute experts and superiors. Management recognized the ambiguity of the boundaries between business units, as more than technical information was needed to make new worlds of technology. It increased social and mental 
uneasiness, urging people to use a variety of viewpoints, to release imaginations and clear the ground for new beginnings, for re-arrangements. Ericsson, by contrast, proceeded in a bureaucratic, un-reflexive and un-playful, manner. In order to generate innovation, it formulated a problem and divided it into parts, rigidly organized the exchange of information among competitive offices in its established organizational formats and rigid procedures. Without confronting real issues, offices protected their turf, hoarding information. Hence, Ericsson proved less renewing.

\section{Conclusion}

In this chapter it has been argued that a key problem in sociology, as in any science, is that sociologists are all too often unaware of the ambivalence of their theorizations of society since they all too often fail to take into account the ambiguity inherent to social existence. In this sense, scientific activities can fail to fulfil their promise of enlightenment, that is, the promise of the liberation from ignorance, and instead reinforce ideologies, sociology's mortal enemy; as well as the enemy of genuine innovation, renewal and revitalization. The deliberate or unconscious ignorance of ambiguity leads to the imposition of models of society on social existence, through bureaucratic implementations and enforcements. In order to develop a truthful sociology or genuine scientific knowledge, that is, one that is true to its own promise, scientific processes such as enquiry, argumentation, clarification and reflection cannot be separated from a broad erudition, empathic understanding and sociological wisdom; only then can sociology be kept out of bureaucratic structures of organizations, in which ambivalence and ambiguity are denied. Instead it must promote dialogue, both within science and within the organizations of society at large, as the appropriate social form for doing sociology. It is the only form that prevents sociologists from alienating themselves from social life, and consequently, from contributing towards reification.

Only through dialoguing is it possible to develop degrees of reflexivity, and to keep theory or theorizing about society, and practice or the social consequences of theory together. Only through dialoguing can sociology manifest, and realize its commitment to the European values of Socratic reason and freedom. At the same time, this commitment is a sine qua non if sociology is not to become the handmaid of power holders; and used as a lethal instrument for manipulating (rationalizing) social existence and for promoting some ideological form of existence in states, corporations, civil society, families, and so forth (like promoting a neo-liberal way of living). In his call for strengthening what he calls 'public sociology', Michael Burawoy (2005a) has ardently voiced the need to reconcile the different sociologies in new sociologies needed for new worlds. Burawoy stresses the urgent need for sociology's presence in the publics, in particular in protest movements that organize themselves to resist neo-liberalized bureaucracies. And indeed, in global capitalist worlds, as contrasted with the more democratic worlds, the social foundations or preconditions for being and doing sociology, and for generating reflexivity, are shaky; universities, in such contexts, tend to become dependent on, and inseparable from, ideological entities. Such entities create their own priorities in which the public mission of representing and realizing both Socratic reason and freedom of action is ignored. The European values are, as always, at risk in social existence, and sociologists face a tough battle to contribute towards the creation of reflexivity, the intellectual sensibility behind theory and practice, so much needed to defeat ideologies and live up to the promise of sociology. 


\section{References}

Agger, Ben (2008) 'Political Sentences: Anti-Intellectualism, Obscurantism and Polymorphous Perversity', Sociological Inquiry 78 (3): 423-430.

Bachika, Reimon and Markus S. Schulz (2011) 'Values and Culture in the Social Shaping of the Future', Current Sociology 59 (2): 107-118.

Bauman, Zygmunt (1991) Modernity and Ambivalence. Cambridge: Polity Press.

Bauman, Zygmunt (2003) Liquid Love: On the Frailty of Human Bonds. Cambridge: Polity Press.

Beck, Ulrich and Elisabeth Beck-Gernsheim (2002) Individualization: Institutionalized Individualism and its Social and Political Consequences. London: Sage.

Beck, Ulrich and Grande, Edgar (2010) 'Varieties of Second Modernity: The Cosmopolitan Turn in Social and Political Theory and Research', British journal of sociology 61 (3): 409-443.

Bloch, Ernst (1983) 'The Dialectical Method', Man and World 16: 281-313.

Burawoy, Michael (2005a) '2004 American Sociological Association Presidential Address: For Public Sociology', The British Journal of Sociology 56 (2): 259-294.

Burawoy, Michael (2005b) 'The Critical Turn to Public Sociology', Critical Sociology 31 (3): 313-326.

Chernilo, Daniel (2011) 'The Critique of Methodological Nationalism: Theory and History', Thesis Eleven 106 (1): 98-117.

Couldry, Nick (2009) 'Does "the Media" Have a Future', European Journal of Communication 24 (4): 437-449.

Emirbayer, Mustafa and Mimi Sheller (1999) 'Publics in History', Theory and Society 28 (1): 145-197.

Goldfarb, Jeffrey C. (2005) 'Dialogue, Culture, Critique: The Sociology of Culture and the New Sociological Imagination', International Journal of Politics, Culture and Society 18: 281-292.

Gouldner, Alvin W. (1973) For Sociology: Renewal and Critique in Sociology Today. London: Allen Lane.

Gouldner, Alvin W. (1976) The Dialectic of Ideology and Technology: The Origins, Grammar and Future of Ideology. London: Macmillan.

Habermas, Jürgen ([1962],2001) The Structural Transformation of the Public Sphere: An Inquiry into a Category of Bourgeois Society. Cambridge MA: MIT Press.

Horowitz, Irving Louis (1993) The Decomposition of Sociology. Oxford: Oxford University Press.

Levine, Donald N. (1985) The Flight From Ambiguity: Essays in Social and Cultural Theory. London: The University of Chicago Press.

Levine, Donald N. (1995) Visions of the Sociological Tradition. London: University of Chicago Press.

Lynd, Robert S. ([1939], 1970) Knowledge for What? The Place of Social Science in American Culture. Princeton: Princeton University Press.

Merton, Robert K. (1976) Sociological Ambivalence and Other Essays. New York: The Free Press. Mills, C. Wright (1956) The Power Elite. Oxford: Oxford University Press.

Mills, C. Wright ([1959], 2000) The Sociological Imagination. Oxford: Oxford University Press. Ossewaarde, Marinus (2007a) 'Sociology Back to the Publics', Sociology 41 (5): 799-812. 
Ossewaarde, Marinus (2007b) 'The Dialectic Between Romanticism and Classicism in Europe', European Journal of Social Theory 10 (4): 523-542.

Ossewaarde, Marinus (2010a) 'The Continuation of the Dialectic in Sociology', Critical Sociology 36 (3): 395-413.

Ossewaarde, Marinus (2010b) 'The Tragic Turn in the Re-Imagination of Publics', Animus: The Canadian Journal of Philosophy and Humanities 14: 43-66.

Ossewaarde, Marinus (2012) Introducing European Societies: Identity and Daily Life. London: Palgrave Macmillan.

Shils, Edward (1980) The Calling of Sociology and other Essays on the Pursuit of Learning. London: University of Chicago Press.

Smith, Graham (2009) Democratic Innovations: Designing Institutions for Citizen Participation. Cambridge: Cambridge University Press. 


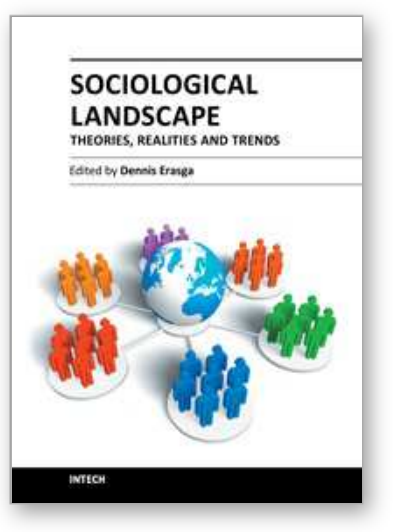

\author{
Sociological Landscape - Theories, Realities and Trends \\ Edited by Dr. Dennis Erasga
}

ISBN 978-953-51-0460-5

Hard cover, 428 pages

Publisher InTech

Published online 28, March, 2012

Published in print edition March, 2012

More than the usual academic textbook, the present volume presents sociology as terrain that one can virtually traverse and experience. Each version of the sociological imagination captured by the chapter essays takes the readers to the realm of the taken-for-granted (such as zoological collections, food, education, entrepreneurship, religious participation, etc.) and the extraordinary (the likes of organizational fraud, climate change, labour relations, multiple modernities, etc.) - altogether presumed to be problematic and yet possible. Using the sociological perspective as the frame of reference, the readers are invited to interrogate the realities and trends which their social worlds relentlessly create for them, allowing them in return, to discover their unique locations in their cultures' social map.

\title{
How to reference
}

In order to correctly reference this scholarly work, feel free to copy and paste the following:

Marinus Ossewaarde (2012). Fulfilling the Promise of Sociology: Some Steps for Generating Reflexivity in Organizations, Sociological Landscape - Theories, Realities and Trends, Dr. Dennis Erasga (Ed.), ISBN: 978953-51-0460-5, InTech, Available from: http://www.intechopen.com/books/sociological-landscape-theoriesrealities-and-trends/fulfilling-the-promise-of-sociology-some-steps-for-generating-reflexivity-in-organizations

\section{INTECH}

open science | open minds

\section{InTech Europe}

University Campus STeP Ri

Slavka Krautzeka 83/A

51000 Rijeka, Croatia

Phone: +385 (51) 770447

Fax: +385 (51) 686166

www.intechopen.com

\section{InTech China}

Unit 405, Office Block, Hotel Equatorial Shanghai

No.65, Yan An Road (West), Shanghai, 200040, China

中国上海市延安西路65号上海国际贵都大饭店办公楼 405 单元

Phone: +86-21-62489820

Fax: +86-21-62489821 
(C) 2012 The Author(s). Licensee IntechOpen. This is an open access article distributed under the terms of the Creative Commons Attribution 3.0 License, which permits unrestricted use, distribution, and reproduction in any medium, provided the original work is properly cited. 